\title{
Histopathological Changes that Induced by Monosodium Glutamate and Sodium Nitrite on the Eyes of White Mice Mus musculus and the Protective Role of Grape Seeds Oil
}

\author{
S. A. A. Al Thanoon ${ }^{1 *}$, A. A. Abed ${ }^{2}$ \\ 1, Department of Biology, College of Education for Pure Sciences, University of Mosul, Mosul, Iraq \\ E-mail: ${ }^{*}$ aliahshgar951@gmail.com, ${ }^{2}$ sanabelalthanoon@gmail.com
}

(Received July 13, 2020; Accepted August 25, 2020; Available online March 01, 2021)

DOI: 10.33899/edusj.2020.127648.1091, (C) 2020, College of Education for Pure Science, University of Mosul.

This is an open access article under the CC BY 4.0 license (http://creativecommons.org/licenses/by/4.0/).

\begin{abstract}
Current study tackled potency of MSG and $\mathrm{NaNO}_{2}$ to induce histopathological changes in eye structure of Swiss-mice and protective role of grape seed-oil against toxicity of these substances may cause.

In this study, 36 adult mice divided into six groups with control. One group was dosed with MSG at $9 \mathrm{~g} / \mathrm{kg}$; another was injected with $\mathrm{NaNO}_{2}$ at $110 \mathrm{mg} / \mathrm{kg}$ for two months, groups with interference of two substances, and two groups with interference of grape seeds-oil with each substance.

Results showed emergence of histopathological lesions. In treatment with MSG, there was wide destruction and damage to photoreceptor cells and outer, inner nuclear layer, separation corneal stroma and gliosis in optic nerve. In treatment with $\mathrm{NaNO}_{2}$, damage was extensive in components of eye; it was noted the appearance of roseat pattern in outer, inner nuclear layer, necrosis of outer plexus layer and contraction of lens fibres. When treating with an interference of MSG and $\mathrm{NaNO}_{2}$, damage was observed to the surface epithelial tissue of cornea, stroma fibres, reduction in fibroblasts, necrosis in some cells of ciliary body, and in retina extensive damage was observed in its layers.

When treating by MSG with oil, increase in the inner plexus vasa, nerve fibres, and the inner nuclear layer was observed and slight damage to the outer pieces of the photoreceptors. When treating with $\mathrm{NaNO}_{2}$, oil, infiltration of inflammatory cells appeared in the ganglion cells, increased vasa, edema and hyperplasia in the epithelium of the lens.
\end{abstract}

Keywords: Monsodium glutamate, Sodium nitrite, Grape seed oil, Eye.

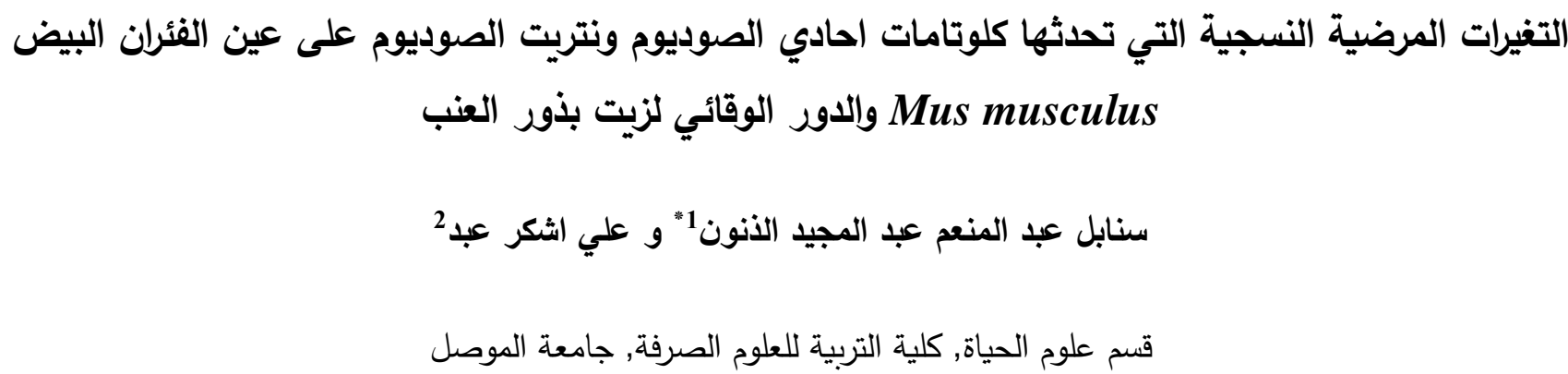




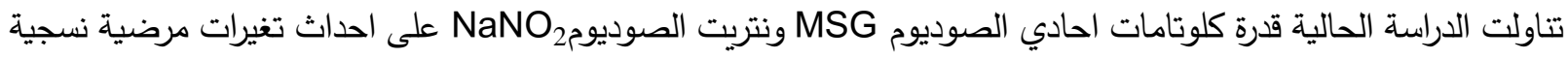
في تركيب العين للفئران السويسرية والدور الوقائي لزيت بذور العنب ضد السمية التي قد تحدثها هذه المواد. استخدمت في الدراسة 36 فارة بالغة قسمت الى ستة مجاميع مع السيطرة. جرعت مجموعة بـ MSG وغم /كغم وحقنت مجموعة بمادة نتريت الصوديوم 110ملغم/كغم لمدة شهرين. ومجموعة بتداخل المادتين، ومجموعتين بتداخل زيت بذور العنب مع كل مادة. بينت النتائج ظهور افات مرضية نسجية، ففي المعاملة بMSG ظهر تحطم واسع وتلف في الخلايا المستقبلة للضوء والطبقة

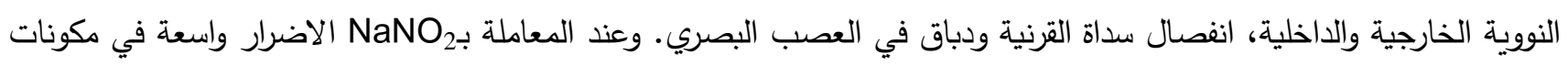
العين، لوحظ ظهور النمط الزهري في الطبقة النووية الخارجية والداخلية، نخر في الطبقة الضفيرية الخارجية وانكماش الياف العدسة.

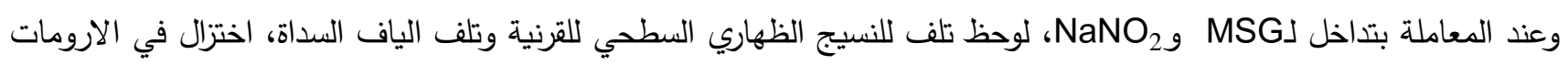
الليفية ونخر في بعض خلايا الجسم الهدبي، وفي الثبكية لوحظ تلف واسع في طبقاتها. وعند المعاملة لـ MSG والزيت، لوحظ زيادة التوعية في الطبقة الضفيرية الداخلية والالياف العصبية والطبقة النووية الداخلية

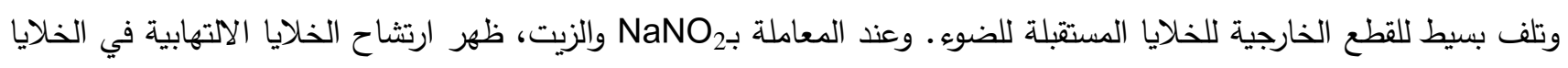
العقدية، زيادة في التوعية، خزب وفرط تتسج في ظهارة العدسة.

الكلمات المفتاحية: كلوتامات احادي الصوديوم، نتريت الصوديوم، زيت بذور العنب، العين.

\section{المقدمة Introduction}

تعرف المضافات الغذائية Food additives على انها مواد كيميائية طبيعية او صناعية تضاف للغذاء وتستخدم على نطاق

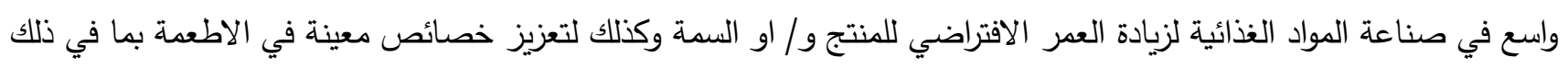

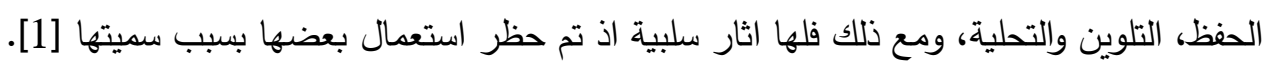
Monsodium glutamate من المضافات الغذائية المستعلة على نطاق واسع في العالم مادة كلوتامات احادي الصوديوم (مادة محسـنة للنكهة) عبارة عن مسـحوق بلوري ابيض اللون [2]. فهو ملح الصـوديوم للحامض الاميني غير الاسـاسـي

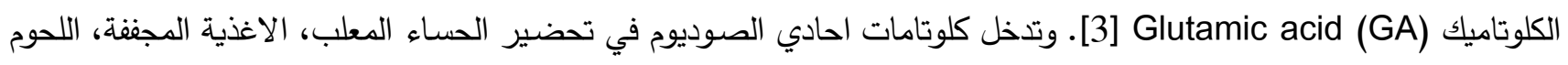

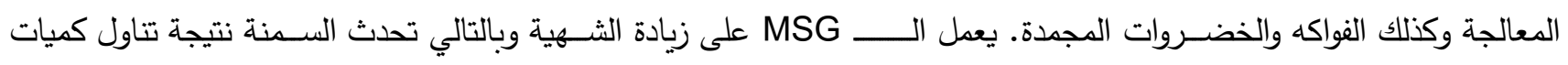

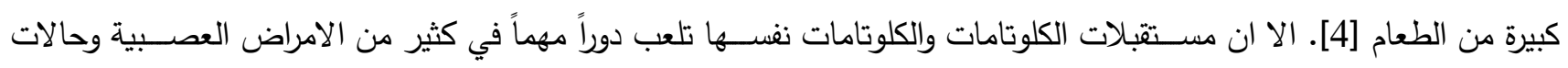

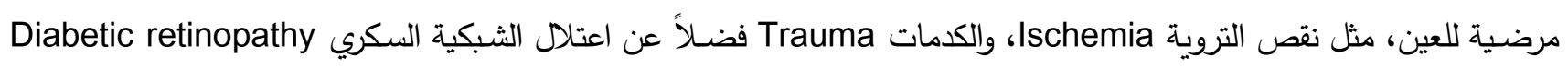

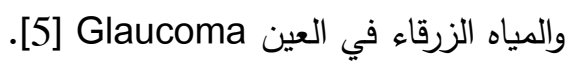

كذلك من المضافات الغذائية ايضا نتريت الصوديوم SaNO2) Sodium nitrite) والذي هو عبارة عن مسحوق بلوري ابيض كلي مائل للاصفرار لله خصائص دوائيه وصناعية فريدة، استخدم في الادوية البشرية والبيطرية كعامل موسع للاوعية الدموية ومضاد

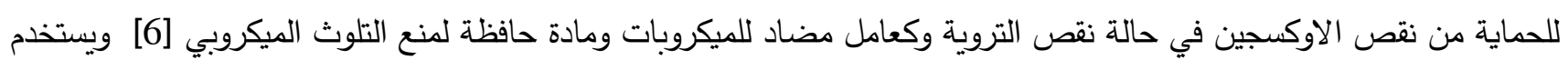
نتريت الصوديوم على نطاق واسع كمادة حافظة Preservative، الا ان نتريت الصوديوم المضاف كمادة حافظة للطعام قد يتفاعل في المعدة مع المركبات الامينية للطعام لتشكيل مركبات Nitrosamine مسببة للسرطان [7]. وبالتالي تؤدي لظهور مركبات وجذور

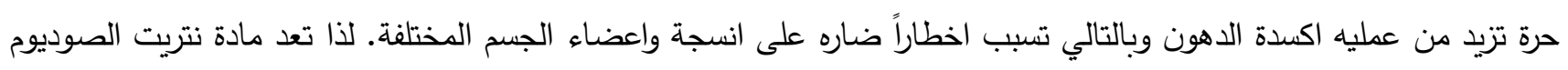
مادة كيميائية سامة، تثكل ضررا عند التعرض لها فهي مهيجة للعين، الرئتين، والجلد وسام عند تتاولها [8]. 
اثبت الابحاث والدراسات العلمية الحديثة فاعلية المركبات النباتية في علاج عدد من الامراض، ويعد العنب من النباتات التي

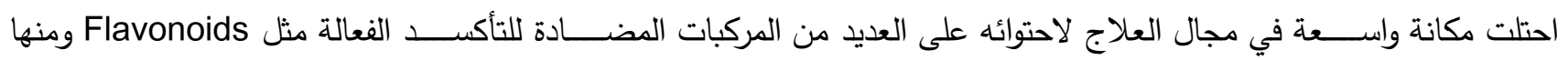
Epicatechin, Catechin, Rutin عديدة ويعتبر مركباً قوياً كمضساد للاكسدة [10,9] فهو غني بـ Proanthocyanidins المركب اكثر فعالية بنسبة 50 مرة من

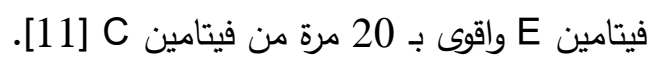
اذ ثبت بان مركبات الفلافونيد الموجودة في زيت بذور العنب تمتلك خصائص مميزة وقوية اثبت فعاليتها لمعالجة الجذور الحرة أي ازالة الجذور الحرة والحد من اكسدة الدهون الغشائية، للحد من حدوث الامراض المرتبطة بالجذور الحرة، ان المكونات الصيدلانية

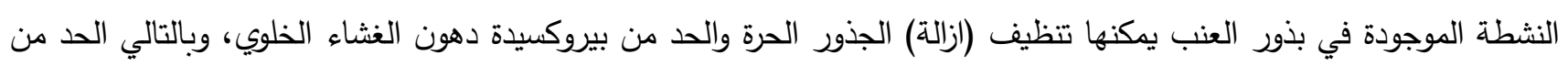
حدوث الامراض المرتبطة بالجذور الحرة [12]. وقد استخدمت في الطب التقليدي للوقاية من الامراض مثل احتثاء عضلة القلب،

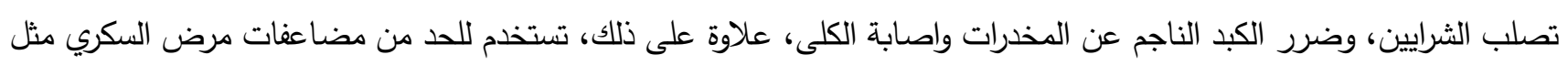

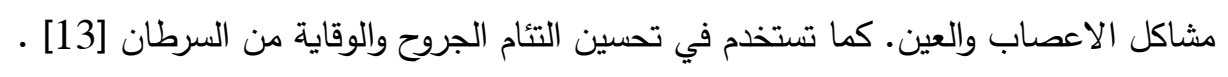

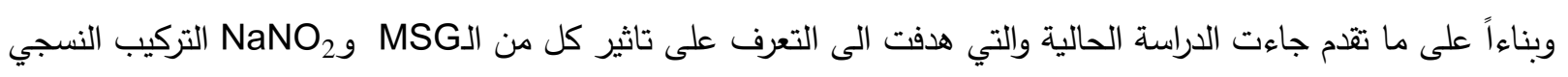
للعين في الفئران البيض السويسرية وكنلك التعرف على قدرة زيت بذور العنب على منع او تقليل هذه الاثار النسجية الضارة.

\section{Materials and Methods المواد وطرائق العمل}

Laboratory Animals الحيوانات المختبرية

اجريت الدراسة الحالية على الفئران البيض السويسرية Mus musculus، اختيرت الفئران بعمر يتراوح (8-12) اسبوع، تراوح

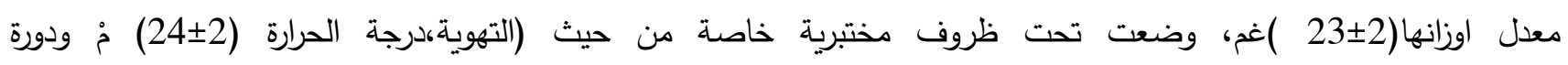
ضوئية Photoperiod (12ساعة ضوء/12 ساعة ظلام) [14] وغذيت بالعليقة الخاصة بها كما واعطيت لها الماء والغذاء بشكل

يومي وعلى نحو مستمر [15].

2.اختيار تراكيز الجرع المستخدمة في الاراسة

\section{Choosing of doses Concentration used in the study}

اختيرت تراكيز الجرع على ضوء الجرعة المميتة الوسطية (LD Median Lethal dose 50 (LD) بالنسبة لكلوتامات احادي

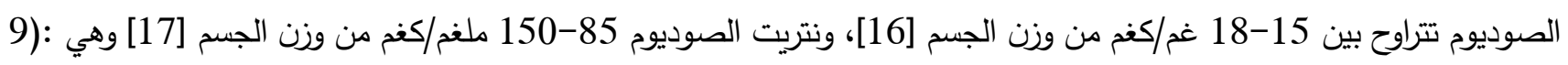

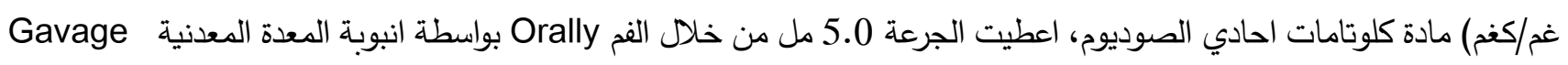

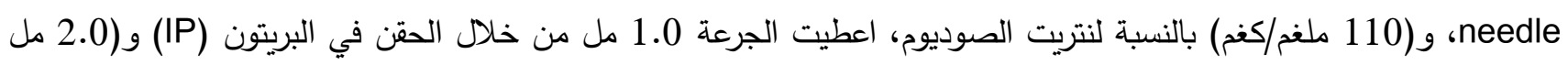

$$
\text { /كغم) الجرعة العلاجية لزيت بذور العنب[18]. }
$$

\section{Experimental Design تصميم التجارب}

$$
\text { تم استخدام (36) فأرة اناث فقط، قسمت الى } 6 \text { مجاميع ثانوية،وعلى النحو التالي: }
$$

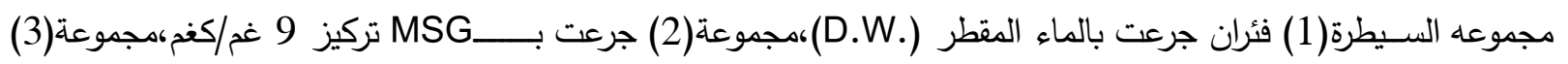

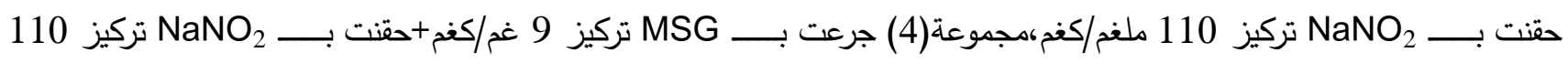

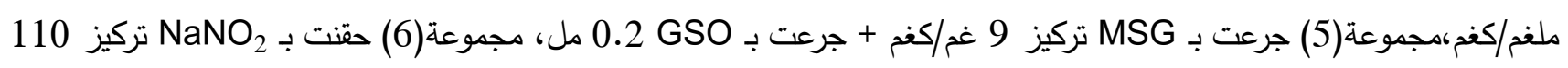
ملغم/كغم + جرعت بـ 0.2 GSO مل،جرعت وحقنت الفئران يومياً لمدة شهرين منتالين. 
Histological sections preparation عضير المقاطع النسجية حضرت المقاطع النسجية بعد مرور شهرين من خلال تخدير وتشريح الفئران لمجموعة السيطرة والمجاميع التجريبية بوساطة [19] Chloroform

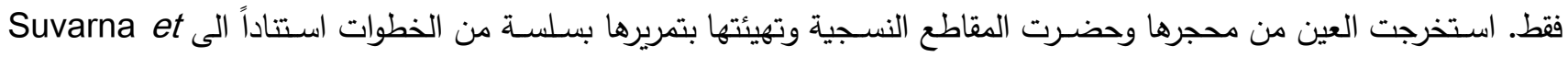
[20].a وكالاتي: تم التثبيت بواسـة الفورمالين المتعادل لمدة 24-48 سـاعة، الغسـل بـــــالماء الجاري لمدة 30 دقيقة،الانكاز

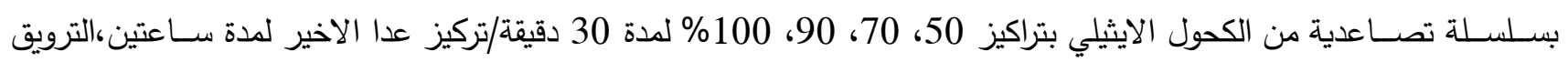

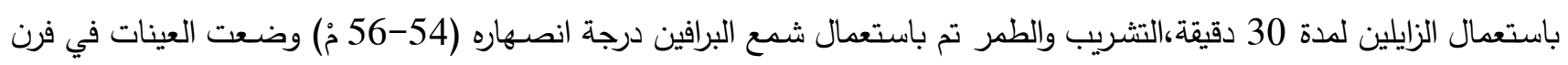

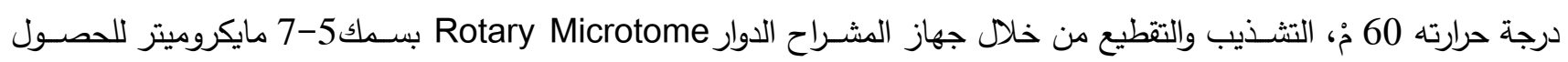
على شـريط حاوي على مقاطع طولية ومستعرضــة وتم ازالة الثـمع من المقاطع النسجية من خلال جرة كوبلن الحاوية على الزايلول

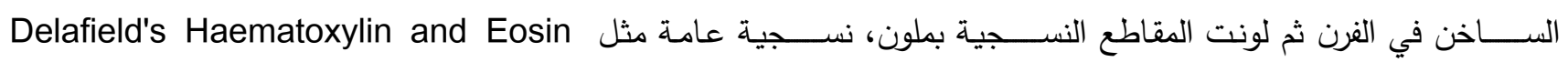
اعتماداً على طريقة الحاج [21] وحملت المقاطع بـ Stain(H\&E) المركب باســـتخدام كاميرا رقمية Digital Camera تربط على المجهر ليتم التصــــير من خلالها وتكون مربوطة بدورها بجهاز

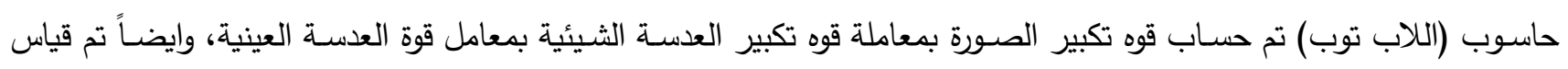
اطوال واقطار الخلايا وسمك طبقات مختلفة لكرة العين من مقاطع المجهر الضوئي باستعمال العدسة المدرجة 7XX ولابت والعدسة الثيئية 4, 10, 40X بعد اجراء المعايرة باستعمال المقياس المسرحي الدقيق وتم استخراج معدل القياس والانحراف المعياري.

\section{Results and Discussion النتائج والمناقشة}

Histological results النتائج النسجية

اوضحت نتائج الفحص المجهري لمقاطع نسيج العين في الفئران البالغة ان العين الطبيعية تتكون من ثلاث غلالات. الغلالة

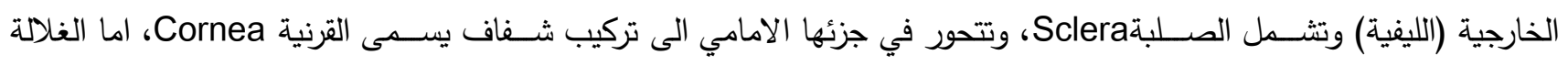

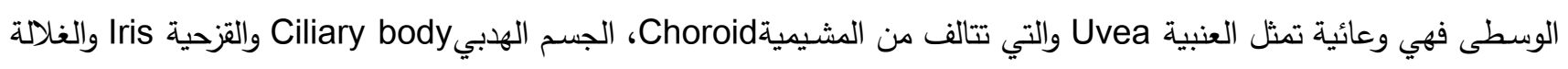

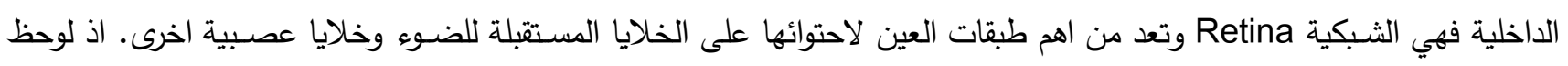

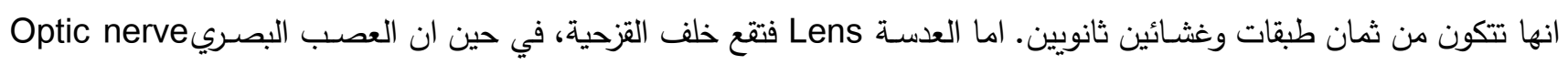

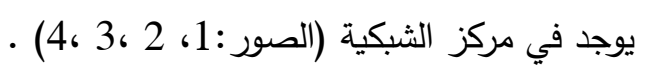

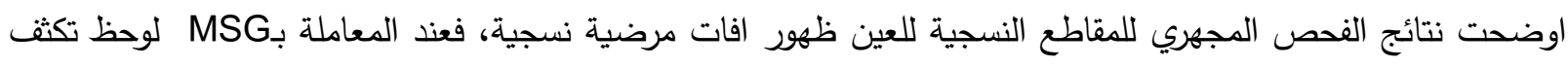
غشاء بروش المحاذي للشبكية وفي الشبكية ظهر تحطم واسع وتلف في الخلايا المستقبلة للضوء والطبقة النووية الخارجية والداخلية وامتداد التلف الى الطبقة الضفيرية الداخلية، تكثف في الطبقة الضفيرية الداخلية والخارجية مع تمزق الطبقة الضفيرية الخارجية (الثكل، 5) اما في القرنية لوحظ انفصال سداة القرنية عن الظهارة السطحية وتلف في بعض خلايا الظهارة السطحية وتكثقها، اختزال طبقات الظهارة السطحية، تلف وتفكك وتكثف وخزب في الياف السداة (الشكل، 6) كما لوحظ دباق في العصب البصري، لفئ تفكلك في اليافه مع تفجي بعضها واختزال في سمك غلافه الخارجي (الثكل، 7). ان الـ MSG محفز سام والذي يمكن ان يغير الوظائف الطبيعية للنقل العصبي في النظم البايولوجية الحيوانية مثل تلف الدماغ الدحتمل، تتكس الثبكية [23,22] ـ ـتؤدي سميّة الكلوتامات

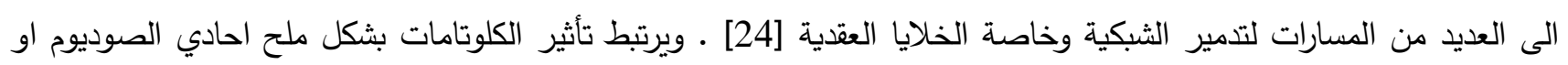
مستقبلات الـ NMDA والتي لها ارتباط وثيق بقوة بنمو العين حيث ان تسم NMDA يستحث موت الخلايا المبرمج في خلايا اماكرين

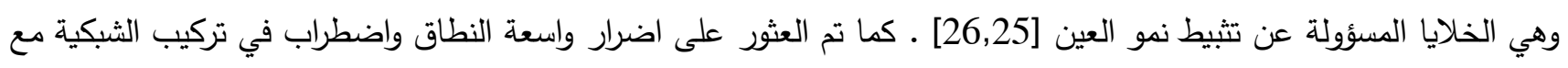


اختزال كبير في سماكة الثبكية الداخلية والخارجية وعدد الخلايا العقدية عند المعاملة بال MSG، كذلك لوحظ اوعية دموية متعددة في بعض طبقات الثبكية [27] ـ اما عند المعاملة بـ NaNO فقد كانت الاضرار واسعة في مكونات العين، اذ لوحظ ظهور النمط الزهري في الطبقة النووية الخارجية والداخلية، تلف القطع الخارجية للخلايا المستقبلة للضوه، نخر في الطبقة الضفيرية الخارجية، اختزال عدد صفوف الطبقة النووية الداخلية وتفكك واختزال في عدد انوية الطبقة النووية الخارجية(الثكل، 8). ولوحظ نخر في الياف العصب البصرية البري وفي

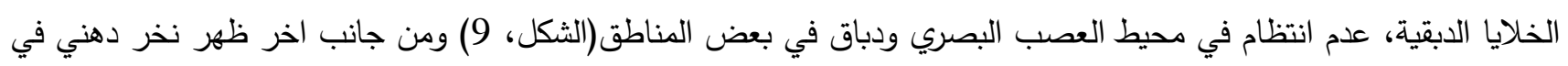
خلايا الجسم الهدبي، تمزق جدار الوعاء الدموي وتوسف بعض الخلايا البطانية لهذا الوعاء (الثكل، 10). كما لوحظ ورّم حبيبي في

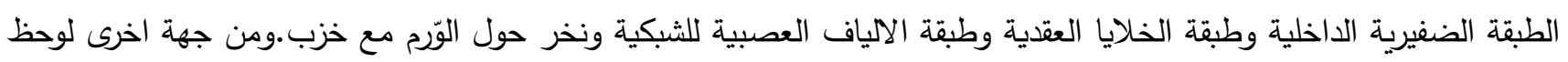
انكماش الياف العدسة وانفصالها عن الدحفة ونخر في بعضها (الثكل، 11) • وفي جزء اخر من الثبكية ظهر اختفاء الخلايا

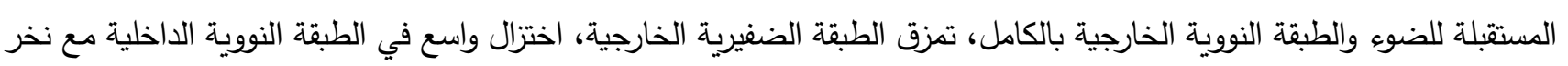

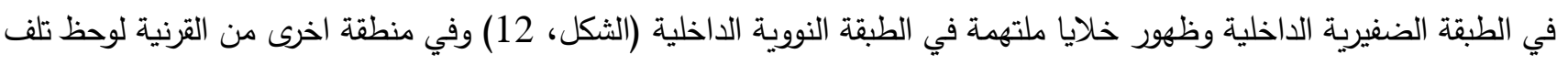
واسع في القرنية ومنه النسيج الظهاري السطحي واختزاله في مناطق اخرى، تنكلك ونحافة في الياف السداة، تكثف غشاء دسمت،

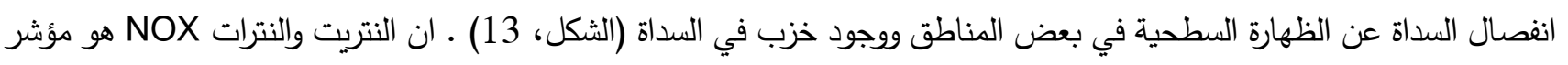

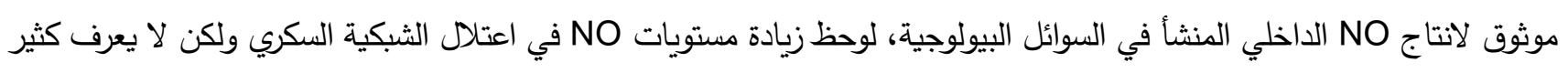

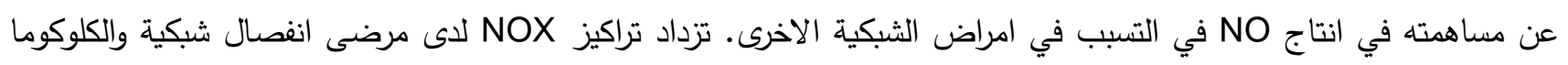

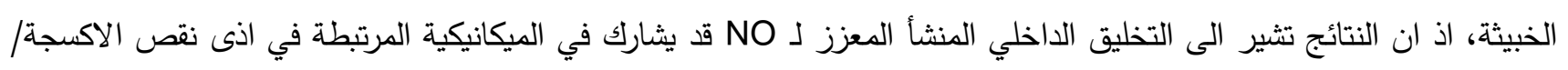

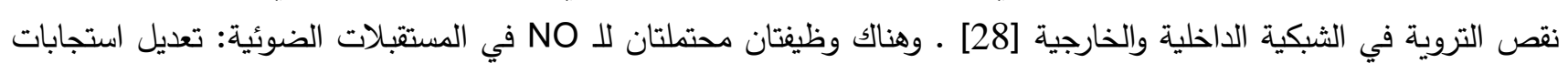
الضوء في المستقبلات الضوئية وتعديل انتقال التثابك في المستقبلات الضوئية الى الخلايا ثنائية القطب والخلايا الافقية، يمكن التوسط في هذه الوظائف من خلال تأثيرات NO على GC او الانزيمات او البروتينات المستهدفة الاخرى في شبكية العين. اما الدور

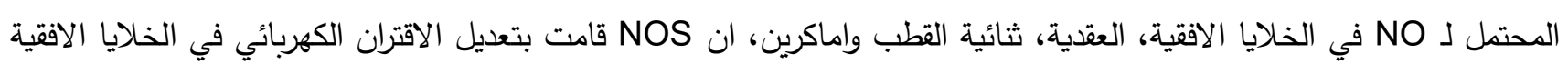

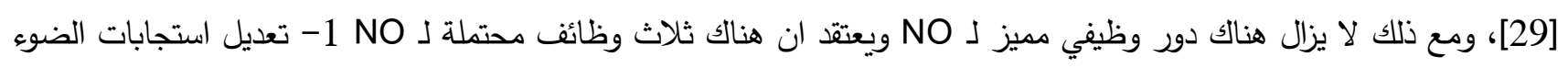

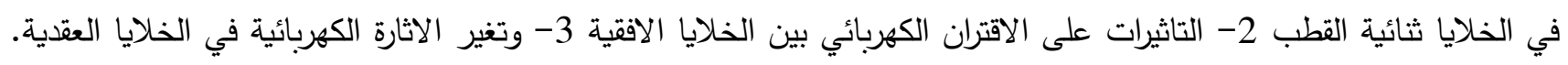

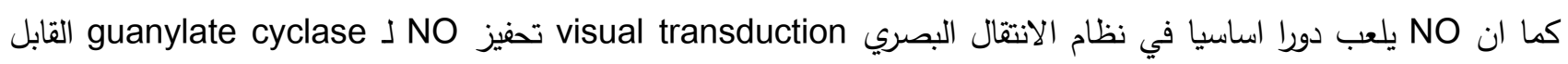

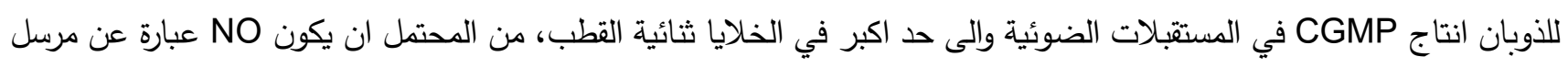
عصبي داخل شبكية العين، لكن اهميته في الانتقال البصري لم توضح بالى بالكامل [30].

وعند المعاملة بتداخل لـNaNO 2 MSG، لوحظ تلف للنسيج الظهاري السطحي للقرنية وتلف الياف السداة وتفككها، اختزال في الارومات الليفية لألياف السداة واختفاء الظهارة البطانية مع وجود خزب بين الآلياف (الثكل، 14) .كما ظهر نخر وانتفاخ في الياف العصب البصري وفرط تتسج في الخلايا الدبقية (دباق) وخزب (الثكل، 15) .ومن جهة اخرى ظهر نخر في بعض خلايا الجسم الهدبي والتزحية وانتفاخ بالوني في بعض الخلايا (الثكل، 16) . وفي الشبكية لوحظ تلف واسع في طبقة الخبل الخلايا المستقبلة

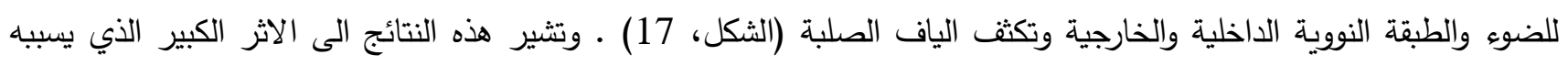
التداخل بين لـ MSG و NaNO كبيرة في العين. ولم نجد على حد علمنا دراسات اخرى تتاولت هذا التداخل والتآزر بين المواد اعلاه مما يدل على لئى ان هذه الدير الدراسة هي الاولى في دراسة تأثير التداخل بينهما على العين. 
اما عند المعاملة لدSG مع الزيت، لوحظ زيادة التوعية في الطبقة الضفيرية الداخلية والالياف العصبية والطبقة النووية الداخلية مع تسك جدران الاوعية الدموية في طبقة الالياف العصبية، نخر في الطبقتين النوويتين وتلف بسيط للقطع الخارجية للخلايا المستقبلة للضوء لجزء من الثبكية (الثكل، 18) .اما في القرنية ظهر تفكك الياف سداة القرنية مع خزب، اختزال في سمك النسيج الظهاري السطحي ونخر في القزحية (الثكل، 19) .وفي العدسة لوحظ فرط تتسج في ظهارة العدسة وتقجي في الالياف العدسية

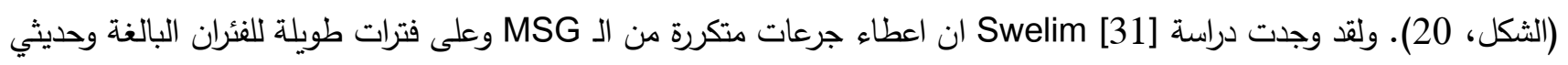
الولادة يؤدي الى تدمير تركيب ووظيفة شبكية العين وذلك لانه يتلف الحاجز الدموي الذي ينظم مرور المواد الى شبكية العين، وبالتالي

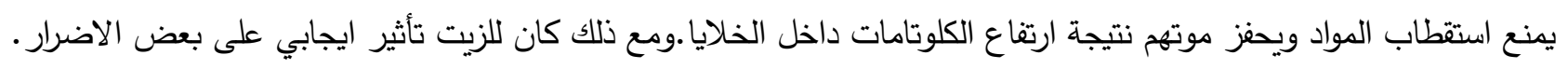
وعند المعاملة بمaNO2 مالزيت، ظهر ارتثاح الخلايا الالتهابية في منطقة الخلايا العقدية، زيادة في التوعية، نخر في جزء

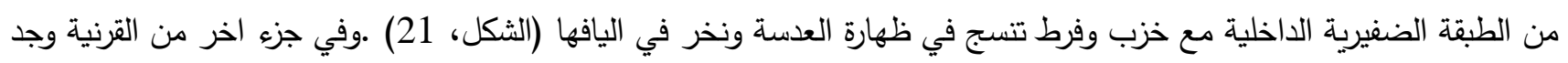

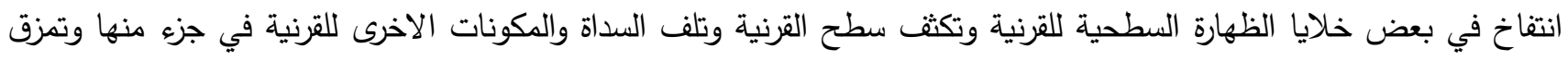

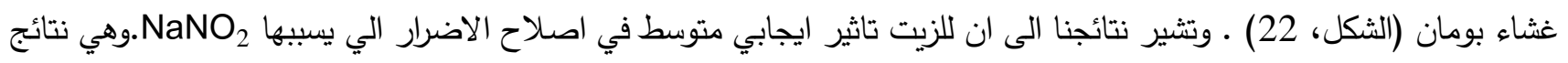

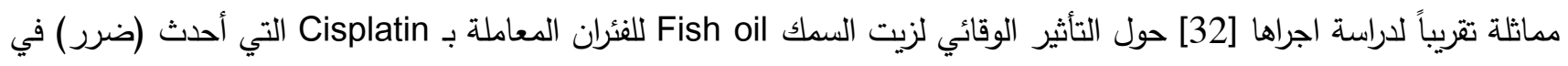
العين، اذ اشارت النتائج للفئران المعاملة بالزيت انه يحمي من التأثيرات السلبية لأنسجة العين.

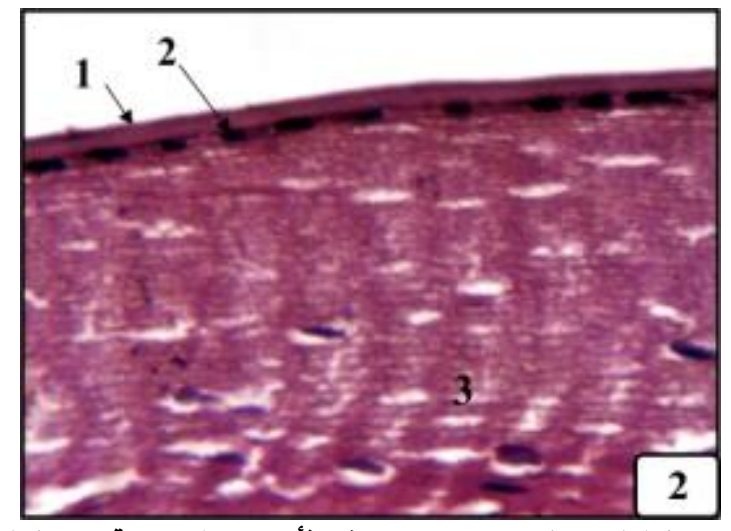

الثكل(2): مقطع نسجي لعين انثى فأر بالغ (مجموعة السيطرة) يوضح:

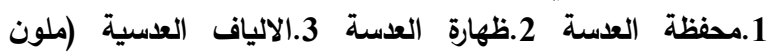
.$(400 \mathrm{X} ، \mathrm{H} \& \mathrm{E}$

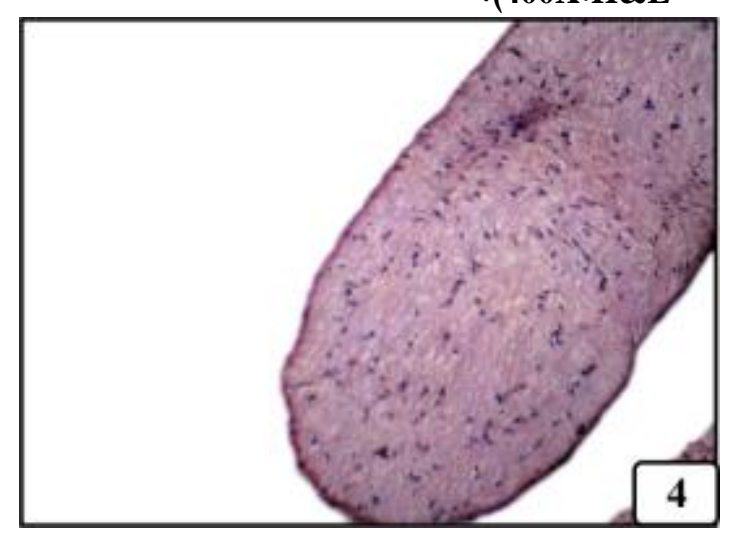

الثكل(4):مقطع نسجي لعين انثى فأر بالغ (مجموعة السيطرة)يوضح:

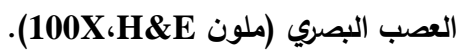

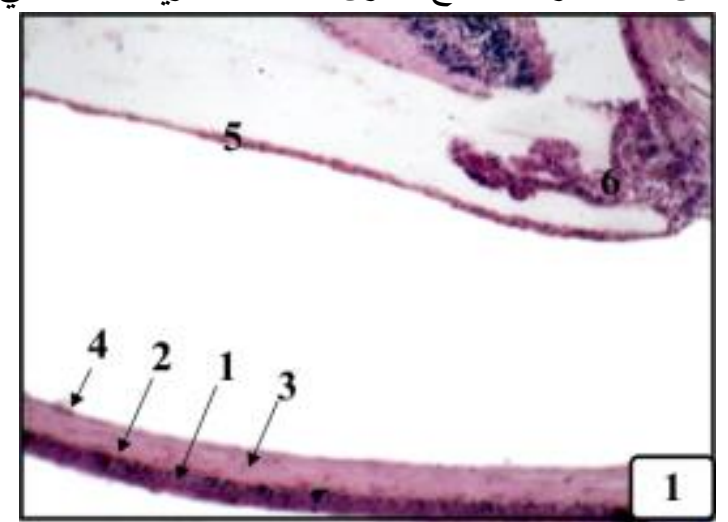

الثكل(1): مقطع نسجي لعين انثى فأر بالغ (مجموعة السيطرة) يوضح:

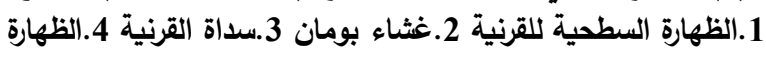

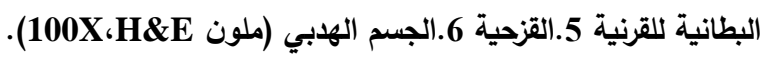

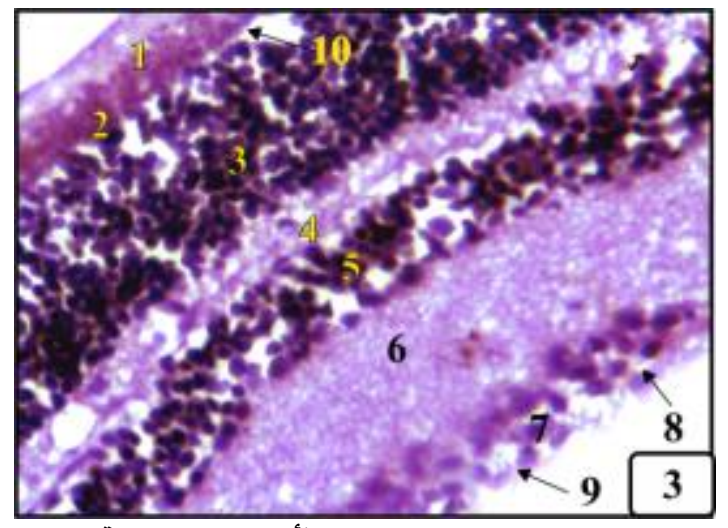

الثكل(3):مقطع نسجي لعين انثى فأر بالغ (مجموعة السيطرة)يوضح:

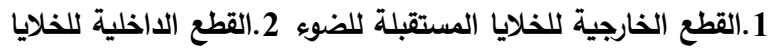

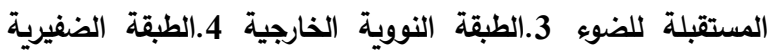
الخارجية 5.الطبقة النووية الإخلية 6.الطبقة الضفية الضفيرية الإخلية

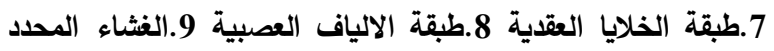

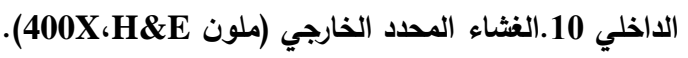




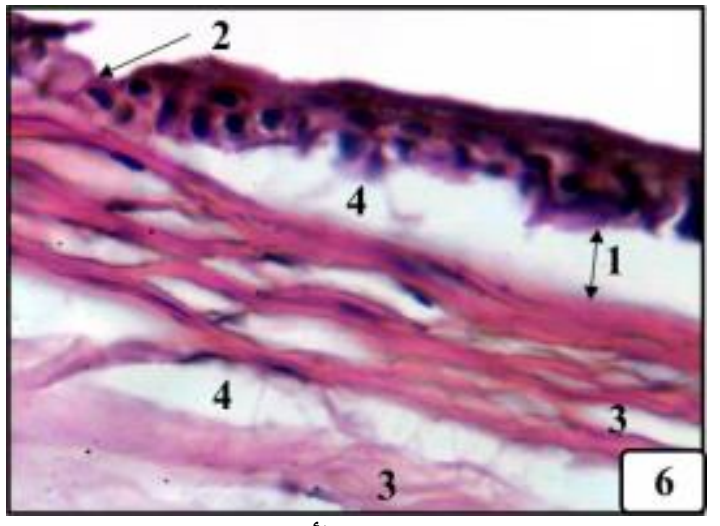

الثكل(6):مقطع نسجي لعين انثى فأر بالغ معامل بـMSG تركيز 9 غم/كفم لمدة شهرين يوضح: 1.انفصال سداة القرنية 2.تلف خلفين الفيا الظهارة

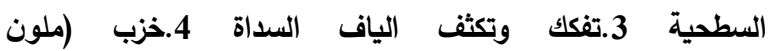
.(400X،\&HE

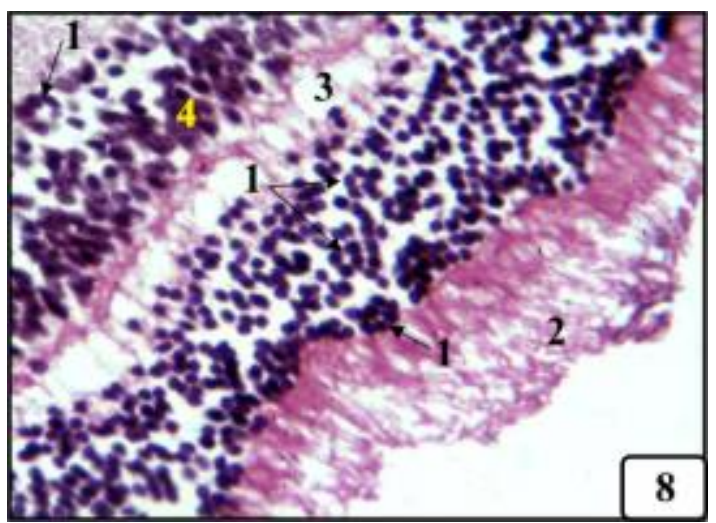

الثكل(8):مقطع نسجي لعين انثى فأر بالغ معامل بـNaNO2تركيز

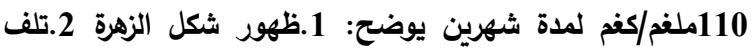
القطع الخارجية للخلايا المستقبلة للضوء 3.نخر 4.الطبقة النووية الاخلية (ملون 400X،H\&E).

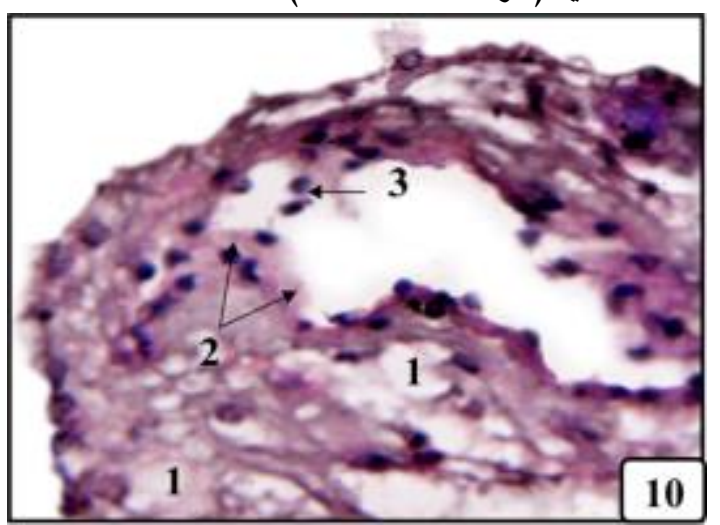

الثكل(10):مقطع نسجي لعين انثى فأر بالغ معامل بـNaNO2تركيز 110ملفم/كفم لمدة شهرين يوضح: 1.نخر دهني 2.تمزق جدار الوعاء 3.توسف (ملون 400X،H\&E).

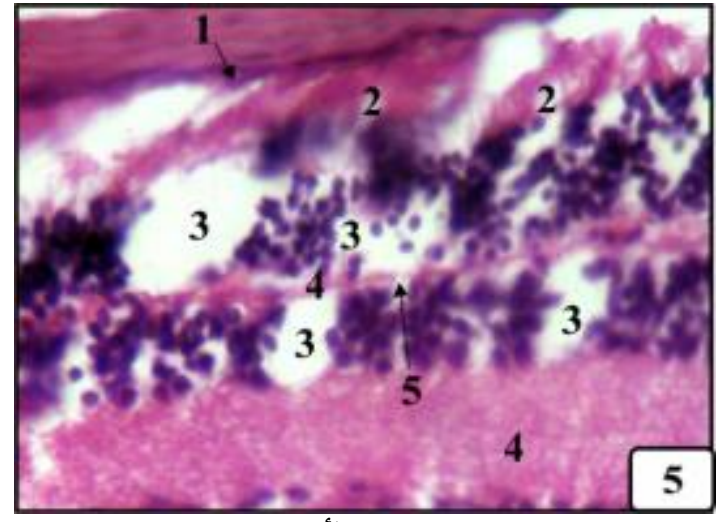

الشكل(5):مقطع نسجي لعين انثى فأر بالغ معامل بـMSG تركيز 9 غم/كغم لمدة شهرين يوضح: 1.تكثف غثاء بروش 2. 2.تحطم الخلايا المستقبلة

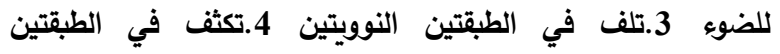
الضفيريتين 5.تمزق الطبقة الضفيرية الخارجية (ملون .(400X،H\&E

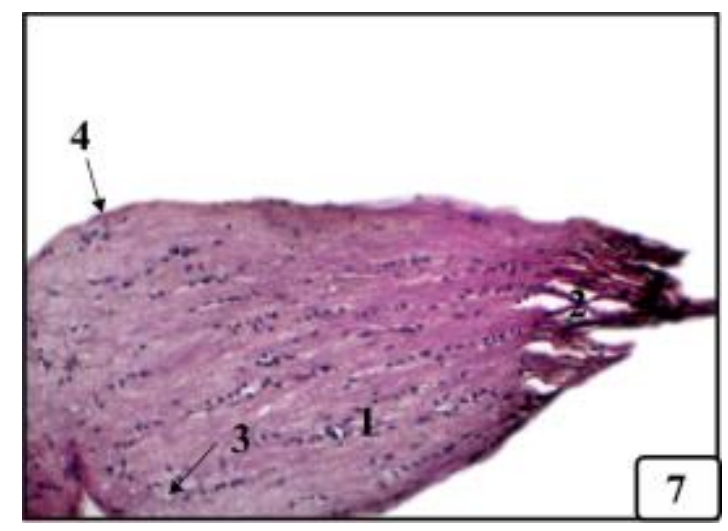

الثكل(7):مقطع نسجي لعين انثى فأر بالغ معامل بـMSG تركيز 9 غم/كغم

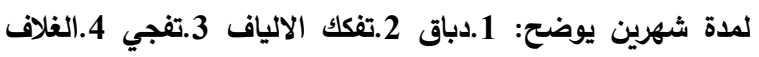
الخارجي (ملون 100X،H\&E).

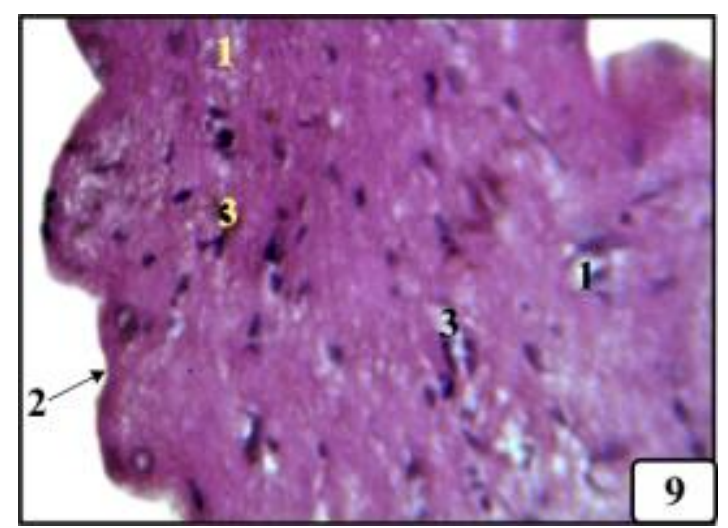

الشكل(9):مقطع نسجي لعين انثى فأر بالغ معامل بـNaNO2تركيز

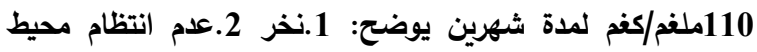
العصب 3.دباق (ملون 400X،H\&E). 


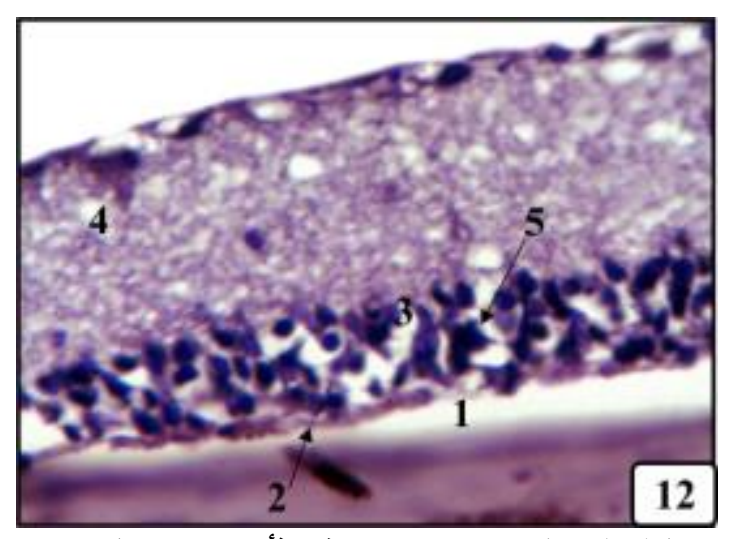

الثكل(12):مقطع نسجي لعين انثى فأر بالغ معامل بـNaNO2تركيز

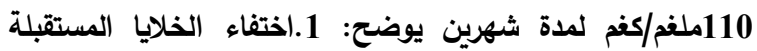
للضوء 2.تمزق الطبقة الضفيرية الخارجية 3.الطبقة النووية الداخلية

4.نخر 5.خلايا ملتهمة (ملون (400X،H\&E).

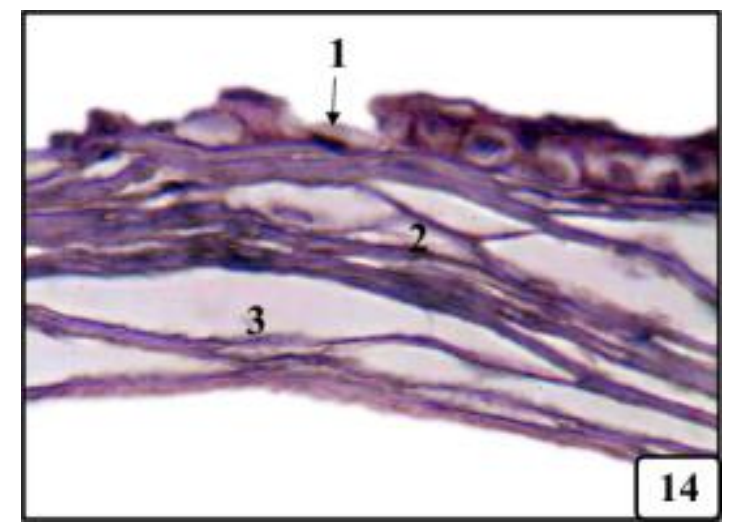

الثكل(14):مقطع نسجي لعين انثى فأر بالغ معامل بالتركيز العالي

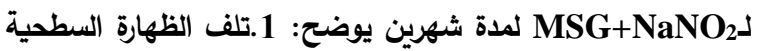
2.الياف السداة 3.خزب (ملون 400X،H\&E).

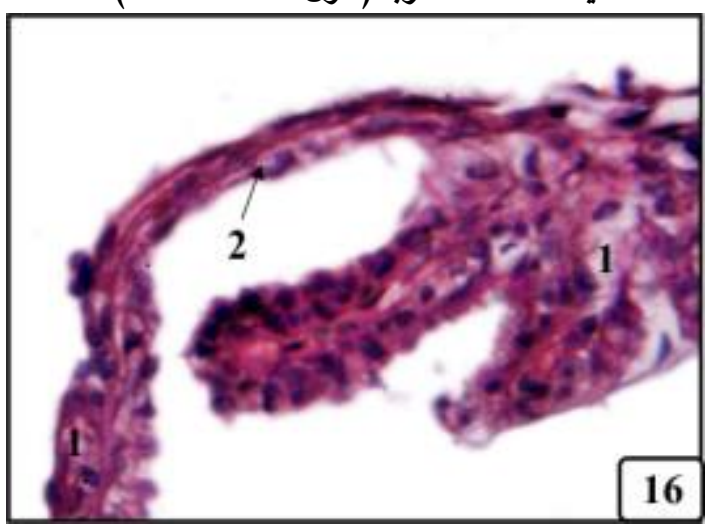

الشكل(16):مقطع نسجي لعين انثى فأر بالغ معامل بالتركيز العالي

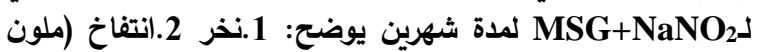

.(400X،H\&E

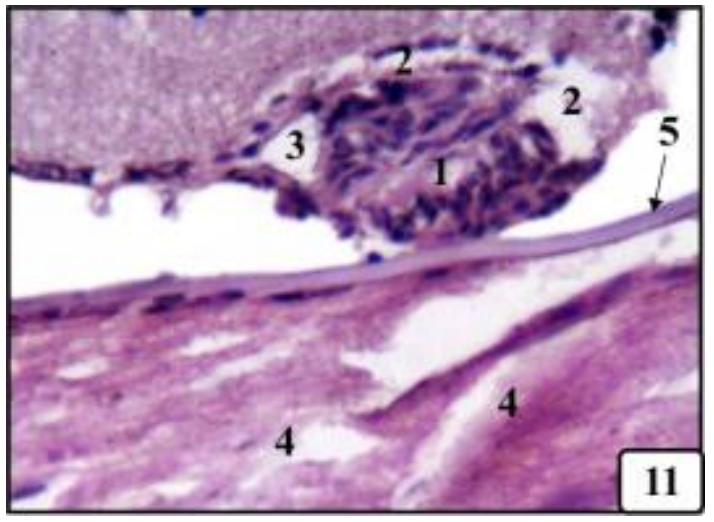

الشكل(11):مقطع نسجي لعين انثى فأر بالغ معامل بـ .NaNO2

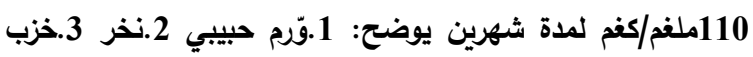
4.الياف العدسة 5.المحفظة (ملون 400X،H\&E).

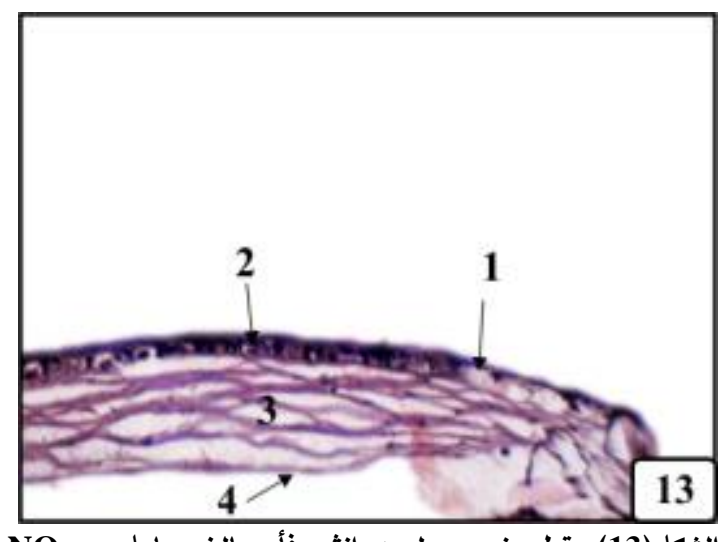

الثكل(13):مقطع نسجي لعين انثى فأر بالغ معامل بـ .NمaNO2:تركيز

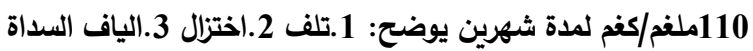
4.غشاء ديست (ملون 100X،H\&E).

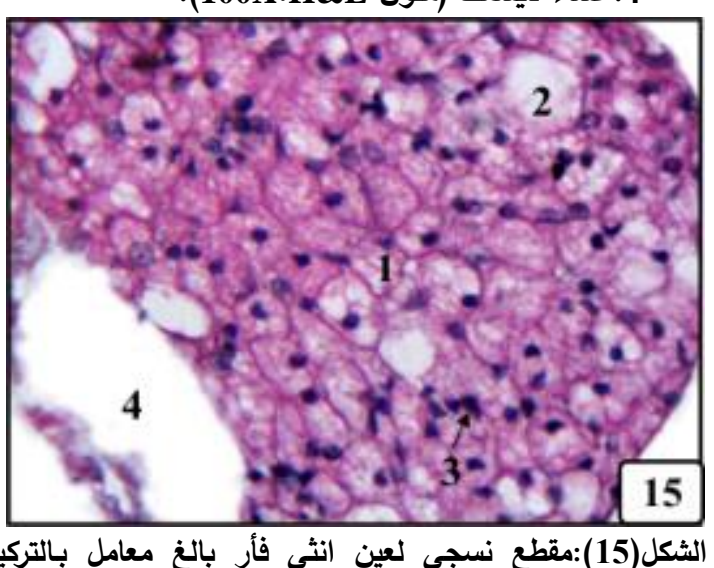

الثكل(15):مقطع نسجي لعين انثى فأر بالغ معامل بالتركيز العالي

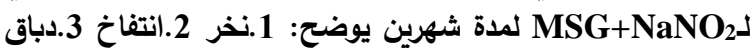

4.خزب (ملون 400X،H\&E). 


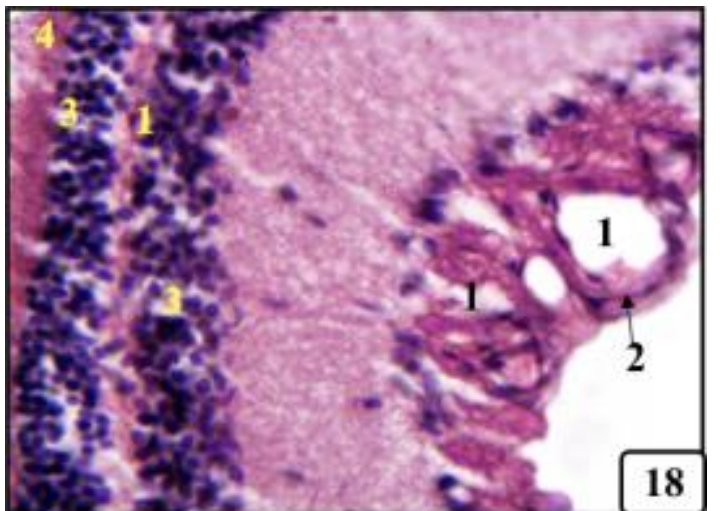

الثكل(18):مقطع نسجي لعين انثى فأر بالغ معامل بالتركيز العالي

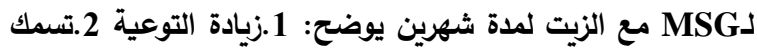

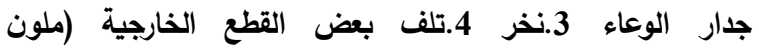
.(400X،H\&E

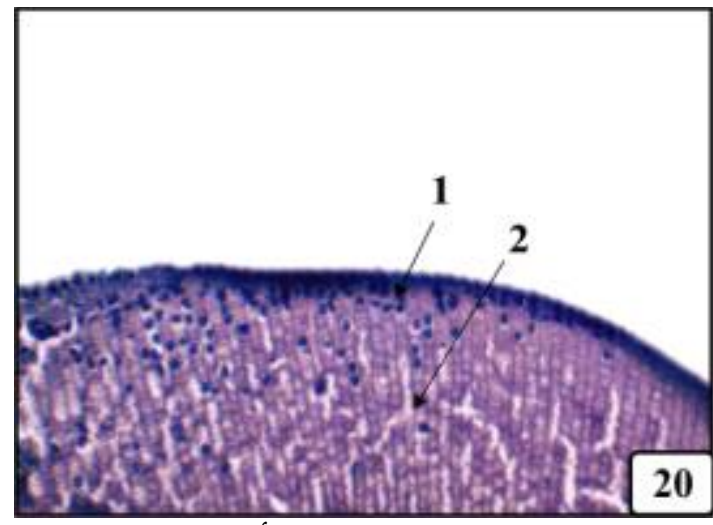

الثكل(20):مقطع نسجي لعين انثى فأر بالغ معامل بالتركيز العالي

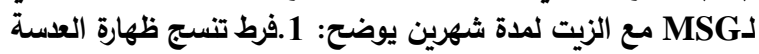
2.تفجي في الالياف العدسية (ملون 100X،H\&E).

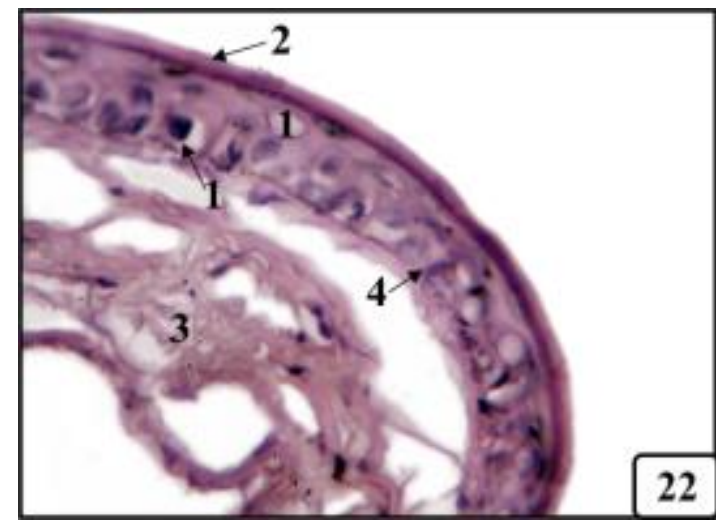

الثكل(22):مقطع نسجي لعين انثى فأر بالغ معامل بالتركيز العالي دـ NaNO2. السطحية 2.تكثف سطح القرنية 3.تلف 4.تمزق غشاء بومان (ملون .(400X،H\&E

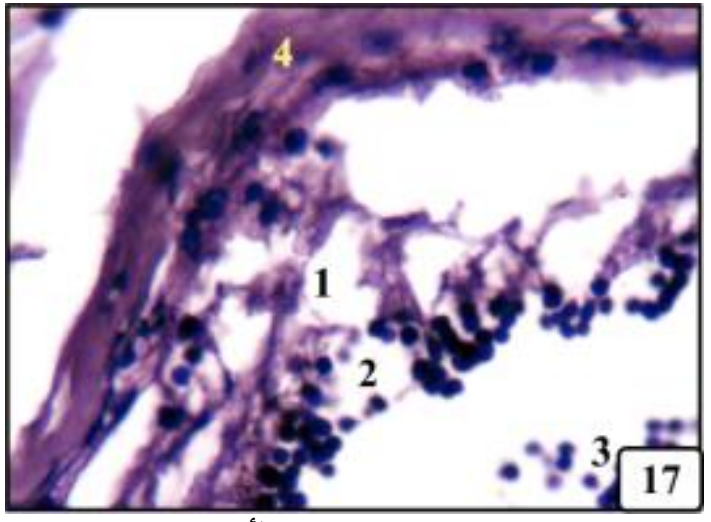

الشكل(17):مقطع نسجي لعين انثى فأر بالغ معامل بالتركيز العالي

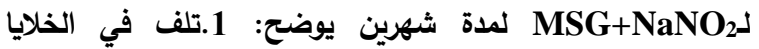

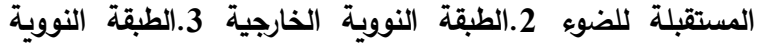
الاخلية 4.تكثف الياف الصلبة (ملون 400X،H\&E).

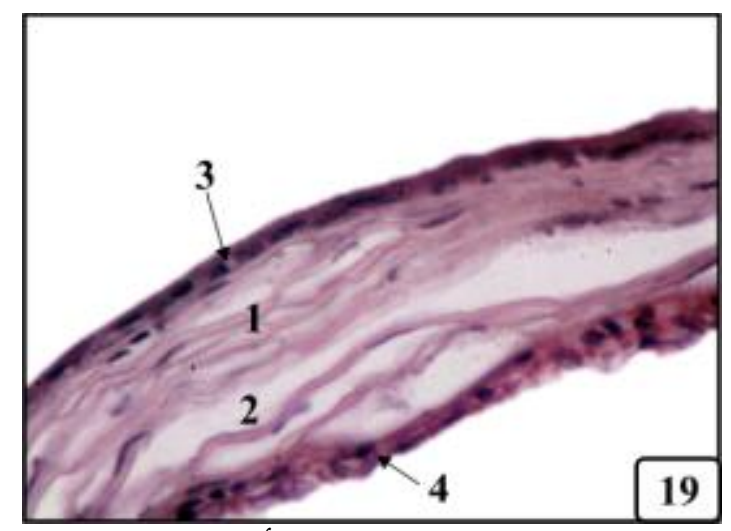

الثكل(19):مقطع نسجي لعين انثى فأر بالغ معامل بالتركيز العالي

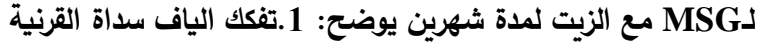

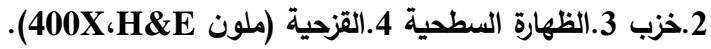

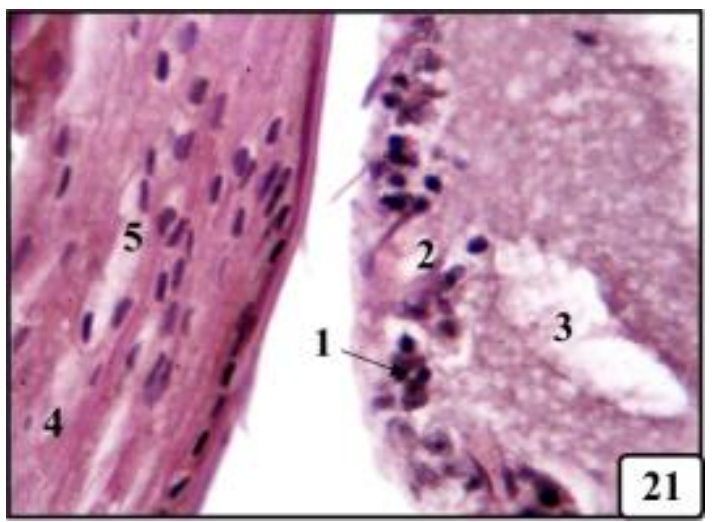

الثكل(21):مقطع نسجي لعين انثى فأر بالغ معامل بالتركيز العالي دالد NaNO2. الالتهابية 2.زيادة في التوعية 3.نخر في الطبقة الضفيرية الداخلية

4.نخر 5.خزب (ملون 400X،H\&E). 


\section{Statistical results النتائج الاحصائية}

يشير جدول (1) الى الاختلافات الاحصائية في سمك الشبكية للمجموعات المعاملة والسيطرة، اظهرت الفئران المعاملة انخفاضاً

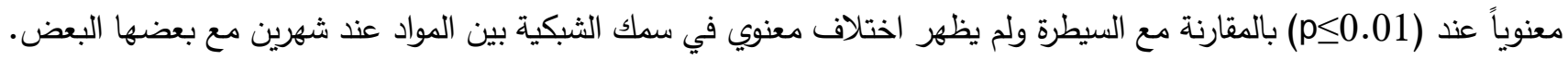

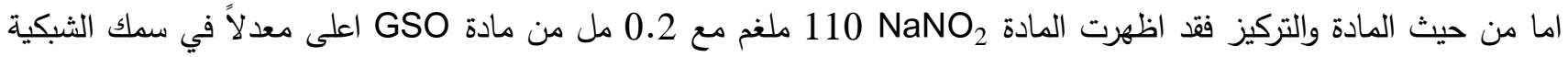
وبفارق معنوي عند (198.47) (1901) بينما لم تظهر بقية المجاميع فروق معنوية فيما بينها.

وتؤيد هذه النتائج ما ذكر في دراسات اخرى، اذ بينت هذه الدراسات انه كلما طالت مدة التعريض فان ذلك يؤدي الى انخفاض

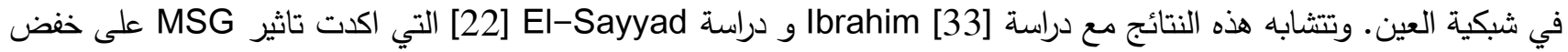
سكك شبكية العين. وتختلف عن نتائج دراسة . Yilmaz et al [34 التي اكدت على دور NaNO على زيادة سك الثبكية. الجدول 1: تأثير كل من MSG و NaNO2 على سمك شبكية العين للفئران البالغة

\begin{tabular}{|c|c|c|c|c|}
\hline 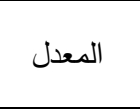 & 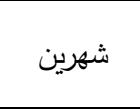 & 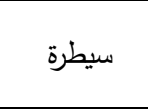 & \multicolumn{2}{|c|}{ المادة والتزكيز } \\
\hline $196.15 \mathrm{~b}$ & $132.65 \mathrm{c}$ & $259.65 \mathrm{~b}$ & 9 غم & MSG \\
\hline $190.65 \mathrm{~b}$ & $121.65 \mathrm{c}$ & $259.65 \mathrm{~b}$ & 110 ملغم & $\mathrm{NaNO}_{2}$ \\
\hline $181.08 \mathrm{~b}$ & $102.52 \mathrm{c}$ & $259.65 \mathrm{~b}$ & \multicolumn{2}{|c|}{9 غم 110 م ملغ MSG MaNO } \\
\hline $198.3 \mathrm{a}$ & $136.95 \mathrm{c}$ & $259.65 \mathrm{~b}$ & \multicolumn{2}{|c|}{9 غم 9.2 + MSG مل GSO } \\
\hline $198.47 \mathrm{~b}$ & $137.30 \mathrm{c}$ & 259.65 & \multicolumn{2}{|c|}{110 ملغ $0.2+\mathrm{NaNO}_{2}$ مل GSO } \\
\hline & $126.21 \mathrm{c}$ & $259.65 \mathrm{a}$ & \multicolumn{2}{|c|}{ المعدل } \\
\hline
\end{tabular}

الارقام المتبوعة بأحرف مختلفة صغيرة تدل على وجود فرق معنوي بين مجاميع التجربة عند مستوى احتمالية (p<0.01) والعكس صحيح حسب اختبار دنكن.

يبين جدول (2) تداخل احصائي واسع بين المجموعة التجريبية والسيطرة في سمك القرنية، وقد ظهر اعلى سمك وبارتفاع

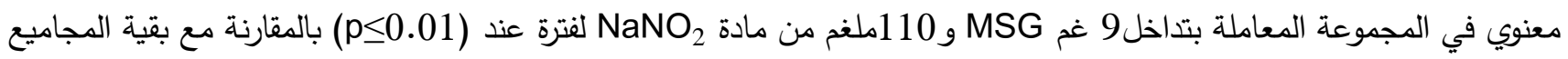

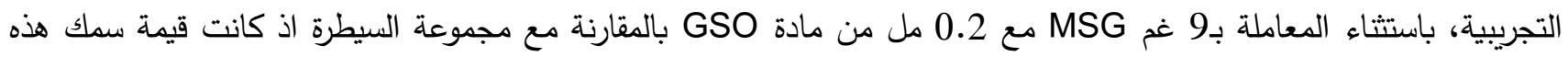

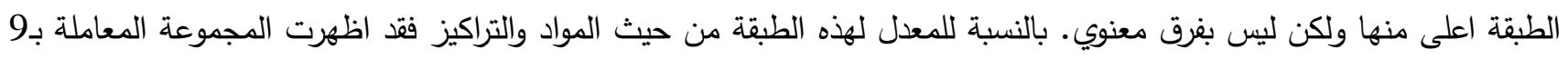

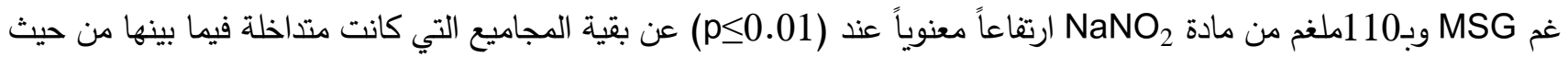

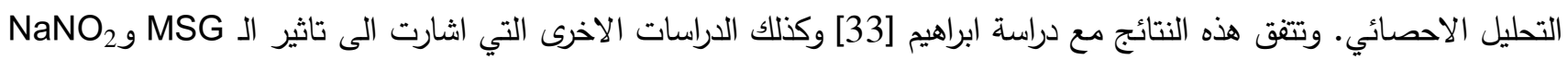

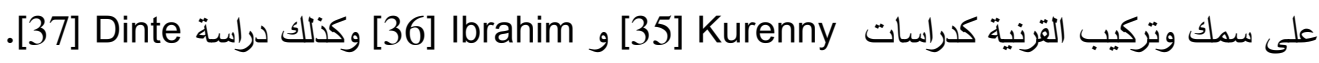
الجدول 2: تأثير كل من MSG و NaNO على سمك قرنية العين للفئران البالغة

\begin{tabular}{|c|c|c|c|c|}
\hline \multirow{2}{*}{ 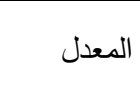 } & \multirow{2}{*}{ 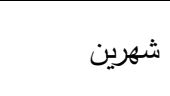 } & \multirow{2}{*}{ 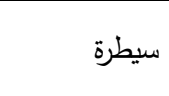 } & \multirow{2}{*}{\multicolumn{2}{|c|}{ المادة والتركيز }} \\
\hline & & & & \\
\hline $120.52 \mathrm{~b}$ & $106.62 \mathrm{c}-\mathrm{f}$ & $134.41 \mathrm{a}-\mathrm{d}$ & 9 (9 & MSG \\
\hline $88.27 \mathrm{bc}$ & $42.12 \mathrm{jk}$ & $134.41 \mathrm{a}-\mathrm{d}$ & 110 ملغ & $\mathrm{NaNO}_{2}$ \\
\hline $153.58 \mathrm{a}$ & $172.74 \mathrm{a}$ & $134.41 \mathrm{a}-\mathrm{d}$ & \multicolumn{2}{|c|}{9 غم 110 ملغ 110 MSG } \\
\hline $145.34 \mathrm{~b}$ & $156.26 \mathrm{ab}$ & $134.41 \mathrm{a}-\mathrm{d}$ & \multicolumn{2}{|c|}{9 غم 0.2 مل MSG } \\
\hline \multirow[t]{2}{*}{$99.92 \mathrm{c}$} & $65.42 \mathrm{~g}-\mathrm{j}$ & $134.41 \mathrm{a}-\mathrm{d}$ & \multicolumn{2}{|c|}{110 ملغ $0.2+\mathrm{NaNO}_{2}$ مل GSO } \\
\hline & $108.63 \mathrm{~b}$ & $134.410 \mathrm{a}$ & \multicolumn{2}{|r|}{ 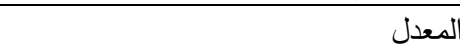 } \\
\hline
\end{tabular}

الارقام المتبوعة بأحرف مختلفة صغيرة تذل على وجود فرق معنوي بين مجاميع التجربة عند مستوى احتمالية (p>0.01) والعكس صحيح حسب اختبار دنكن. 
يمكن الاستتاج من الدراسة الحالية ان لكلوتامات احادي الصوديوم ونتريت الصوديوم قدرة على احداث تغيرات مرضية نسجية

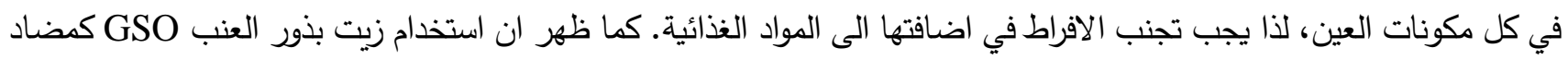
الاككدة Antioxidants كان له دور وقائي بتخفيف من شدة هذه الافات المرضية النسجية.

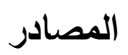

1. Linke BGO.,Casagrande TAC and Cardoso LAC., African. Biotech.,17(10):306-310(2018).

2. Hamza RZ. and Diab AA.,Toxi. Rep.,7:254-260 (2020).

3. Al-Mosaibih MA.,Life. Sci.,10(25):35-42 (2013).

4. Fernandez JA. and Hernandez T.,.An R Acad Nac Med.,122(2):341-55(2005).

5. Sudha NB., Raju AB. and Ashok A., Ind.Phar.Edu. \& Res.,50(2s):S52-S58. (2016).

6. Al-Hiti SM.,Hussain AH. and Al-Zabaidy AF., Inter. Pharma. Scie. \& Rese.,9(2) 483-489 (2018).

7. Zheng W. and Wang SY., Agric. Food Chem.,49 (11):5165-5170 (2001).

8. Gladwin MT., Crawford JH. and Patel RP.,Free Radic. Biol. Med., 36 (6):707-717(2004) .

9. Hasona N. and Hussien T., Intercu. Ethnopharm .,6(4) (2017).

10. Hasseeb MM., Al-Hizab FA. and Hamouda MA.,Pak. Vet. ., 33, 282-286. (2013).

11. Garavaglia J., Markoski MM., Oliveira A. and Marcadenti A., Nutrit. Meta. 16(9):59-64 (2016).

12. Esrafil M., Layasadat, K. and Maasoumeh MZ.,Iran. Pharm. Res.,14(1): 329-334 (2015).

13. Hasona NA., Alrashidi AA., Aldugieman TZ., Alshdokhi AM. and Ahmed MQ.,Toxics. 5(11)(2017).

14. Abdul-Fattah J. H., Ph. D. Thesis, College of Science. University of Mosul(2004) (In Arabic).

15. Terry KK., Stedman DB., Bolon B. and Welsch F.,Teratol., 54(5):219-29 (1996).

16. Bera TK., Kar SK., Yadav PK., Mukherjee P., Yadav S. and Joshi B., Pharma. Sci., 5(4):139144(2017).

17. Ansari FA.,Ali SN., Khan AA. and Mahmood R.,PLoS .One. 6;12(4)(2017).

18. AL.Jeboory SKA., Al Taae EHY. and AL. Naimi RA.,Iraqi . Vet. Med., 36(1): 85-98 (2012).

19. Al-Sultan R.G., Ph.D.Thesis,College of Education for Pure Sciences.University of Mosul (2017). (In Arabic).

20. Suvarna S. K., Layton C. and Bancroft J. D.,"Bancroft's theory and practice of histological techinques". $8^{\text {th }}$. Elesvier.China. (2019).

21. A-Hajj A."Optical laboratory preparation." $1^{\text {st }}$ ed .Amman:Dar Al-Massera:(2010).

22. El-Sayyad HI., El-Naga AM. and Khalifa SA., Drug Metabo. \& Toxi.,7(4):1-7 (2016).

23. Foran L., Blackburn K. and Kulesza RJ., Neuro science, 344: 406-417. (2017).

24. Sucher NJ., Lipton SA. and Dreyer EB.. Vis. Res., 37: 3483-3493 (1997).

25. Fischer AJ., Seltner RL., Poon J. and Stell WK.,Comp. Neurol. 393:1-15 (1998).

26. Ali HS., El-Gohary A., Metwally FG., Sabra NM. and El-Sayed A., Global Pharma.,6(3):148159 (2012)

27. El-Gohari KMA., Bahei-Eldin IA., Habib EMK., Saad SA., Rady HYS. and Said AMA., Ophthal. Soci. 109(3):135-144 (2016).

28. Mankowska A., Rejdak RA.,Zarnowski T.,Zielinska E.and Zagorski Z., Inves. Ophthal. \& Vis. Scie.46(13) (2005).

29. Miyachi EI., Miyakawa A. and Murakami M., Neu.scie. Rese.,15(Suppl.), S41-S49 (1991). 
30. Goldstein IM, Ostwald P., and Roth S.,Visi. Res.,36(18):2979-94 (1996).

31. Swelim HH., Egypt .Med.Lab. Sci.13(2):45-71 (2004).

32. Gul Baykalir B., Ciftci O., Cetin A. and Basak Turkmen N.Cutan. Ocul. Toxi.,37(2):151-156 (2018).

33. Ibrahim ,M.N.Ph.D.Thesis, College of Sciences.University of Tikrit (2017). ～(In Arabic).

34. Yilmaz G., Esser P., Kociek N. and Heimann K.,Eye.,14:899-902(2000).

35. Kurenny DE., Moroz LL., Turner RW. Sharkey KA. and Barnes S., Neuron.,13.315-324. (1994).

36. Ibrahim MN., Abd All alluah SA.,Tikr.Pure. Scien.,22(7):49-59 (2017) .

37. Dinte E.,Vostinaru O., Samoila O., Sevastre B. and Bodoki E. ,Coatings.,10(36):1-14 (2020). 